\title{
Variabilidade entre genótipos de feijoeiro na eficiência no uso do fósforo
}

\author{
Variability between genotypes of common bean for the efficiency of using phosphorus
}

\author{
Regina Maria Quintão Lana ${ }^{1}$ Luiz Antônio Zanão Júnior ${ }^{2}$ Núbia Maria Correia ${ }^{3}$ \\ Ângela Maria Quintão Lana ${ }^{4}$
}

\section{RESUMO}

A utilização da variabilidade genética em feijoeiro (Phaseolus vulgaris L.) para eficiência na absorção e utilização de fósforo se mostra como uma alternativa para contornar a deficiencia deste elemento em solos de cerrado. Para detectar tais eficiências, foi desenvolvido um experimento em casa de vegetação na Universidade Federal de Uberlândia-MG, entre julho e agosto de 1997. O delineamento experimental foi de blocos casualizados com quatro repetições, em esquema fatorial 8 × 2. Foram avaliados oito genótipos de feijoeiro (BAT 477, Carioca MG, Emgopa 201, Jalo Precoce, Pérola, Rosinha, Roxo e Xamego) e duas doses de $\mathrm{P}_{2} \mathrm{O}_{5}\left(24\right.$ e $\left.120 \mathrm{mg} \mathrm{dm}^{-3}\right)$. Após 45 dias da germinação, foram analisadas a produção de matéria seca da parte aérea e das raízes dos genótipos; conteúdo de fósforo na parte aérea e das raízes; razão raiz:parte aérea e a eficiência no uso do fósforo (valor $\alpha$ ), classificando-os em quatro grupos: eficientes e responsivos, não eficientes $e$ responsivos, eficientes e não responsivos e não eficientes e não responsivos. Os genótipos classificados como eficientes na absorção e utilização de fósforo foram BAT 477, Jalo Precoce e Roxo, enquanto que os classificados como responsivos foram os genótipos Carioca MG, Jalo Precoce, Pérola e Roxo.

Palavras-chave: Phaseolus vulgaris L., nutrição mineral, fósforo, feijão, raiz.

\section{ABSTRACT}

The use of the genetic variability in common bean (Phaseolus vulgaris L.) for its efficiency in the absorption and use of phosphorus arises as an alternative to avoid the deficiency of this element in Cerrado soils. Aiming at detecting such efficiencies, an experiment was carried out in a greenhouse at the Federal University of Uberlândia-MG, from July to August 1997. The experimental design was of complete randomized blocks with four replications, on an $8 \times 2$ factorial scheme. Eight genotypes of common bean (BAT 477, Carioca MG, Emgopa 201, Jalo Precoce, Perola, Rosinha, Roxo e Xamego) and two levels of $\mathrm{P}_{2} \mathrm{O}_{5}$ (24 and $120 \mathrm{mg} \mathrm{dm}^{-3}$ ) were evaluated. The production of dry mass of shoots and roots of genotypes, content of phosphorus in shoots and roots; root:shoot ratio and the efficiency in the use of the phosphorus (a value), were determined at 45 days after germination. The genotypes were classified in four groups: efficient and responsive, not efficient and responsive, efficient and not responsive and not efficient and not responsive. The genotypes were classified as efficient in the absorption and use of phosphorus BAT 477, Jalo Precoce and Roxo and the genotypes Carioca MG, Jalo Precoce, Perola e Roxo were classified as responsive.

Key words: Phaseolus vulgaris L., mineral nutrition, phosphorus, common bean, root.

\section{INTRODUÇÃO}

O feijoeiro é uma das principais culturas plantadas na entressafra, em sistemas irrigados, nas áreas de cerrado (BARBOSA FILHO et al., 2001). Essas áreas possuem solos caracterizados pela baixa fertilidade natural, com elevada acidez e presença de

${ }^{1}$ Instituto de Ciências Agrárias, Universidade Federal de Uberlândia (UFU). Av. Amazonas s/n, Bloco 4C, Sl. 09, Campus Umuarama, Caixa Postal 593, 38400-902, Uberlândia, MG, Brasil. E-mail: rmqlana@iciag.ufu.br. Autora para correspondência.

${ }^{2}$ Programa de Pós-graduação em Solos e Nutrição de Plantas da Universidade Federal de Viçosa (UFV), Viçosa, MG, Brasil. E-mail: luizantoniozanao@yahoo.com.

${ }^{3}$ Programa de Pós-graduação em Agronomia (Produção Vegetal), Universidade Estadual Paulista (UNESP), Campus de Jaboticabal, SP, Brasil. E-mail: nubiacorreia@hotmail.com.

${ }^{4}$ Departamento de Zootecnia, Universidade Federal de Minas Gerais (UFMG), Belo Horizonte, MG, Brasil. E-mail:lana@vet.ufmg.br. 
$\mathrm{Al}^{+3}$ (ERNANI et al., 2002). A alta capacidade de retenção de fósforo nestes solos torna-se uma das principais limitações à produtividade agrícola. A alternativa empregada como forma de minimizar esse problema de custo elevado é o uso de corretivos e fertilizantes (OLIVEIRA et al., 1987), adequando o solo à planta. Uma nova estratégia seria detectar e possivelmente explorar o uso das diferenças genotípicas em feijoeiro para a eficiência na absorção e utilização do fósforo, reduzindo gastos com fertilizantes, adequando a planta ao solo.

A variabilidade entre espécies e variedades de plantas com relação à capacidade de absorção e utilização de fósforo tem sido demonstrada por muitos trabalhos em relação a maioria das culturas, como feijão (OLIVEIRA et al., 1987), soja (CASTELIS et al., 1985; MARTINEZ et al., 1993a e 1993b), milho (MACHADO et al., 1999), arroz (FURLANI et al., 1984; FAGERIA, 1989), trigo(ABICHEQUER \& BOHEN, 1998; PALMER \& JESSOP, 1977) е cacau (ROSAND \& MARIANO, 1985).

A eficiência de absorção de $\mathrm{P}$ está relacionada à capacidade de absorção de maiores quantidades de $\mathrm{P}$ com um mínimo investimento em crescimento radicular, e a eficiência de utilização é a habilidade relativa de produção de biomassa para cada unidade de $P$ acumulado (ELLIOTT \& LÄUCHLI, 1985). A distinta capacidade de absorção de fósforo entre genótipos pode ser causada pela morfologia do sistema radicular (O’TOOLE \& BLAND, 1987); razão raiz:parte aérea (SMITH et al., 1990); distribuição, arquitetura e raio radicular (INFORZATO \& MIYAZAKA, 1963; BONSER et al., 1996; ARAÚJO et al., 1998) e eficiência da simbiose com micorrizas (SMITH et al., 1992).

A escolha de cultivares de feijão que porventura possuam maior eficiência na absorção e utilização de fósforo passa a ser alternativa útil e viável, para cultivos instalados sob condições de baixa disponibilidade deste nutriente. Diante disso, este trabalho teve como objetivo avaliar oito genótipos de feijoeiro quanto à eficiência na absorção e utilização de fósforo.

\section{MATERIAL E MÉTODOS}

O experimento foi conduzido em casa de vegetação da Universidade Federal de Uberlândia-MG, no período de julho a agosto de 1997. Utilizaram-se vasos contendo $16 \mathrm{~kg}$ de areia. Essa areia foi previamente lavada com água potável e água deionizada, e sua análise química pelo método descrito por SILVA et al. (1999) revelou apenas traços de fósforo.
O delineamento experimental foi o de blocos ao acaso, em esquema fatorial $8 \times 2$, sendo oito genótipos de feijoeiro (BAT 477, Carioca MG, Emgopa 201, Jalo Precoce, Pérola, Rosinha, Roxo e Xamego) e duas doses de $\mathrm{P}_{2} \mathrm{O}_{5}$ (24 e $120 \mathrm{mg} \mathrm{dm}^{-3}$ ) em quatro repetições. Foram semeadas quatro sementes por vaso, com desbaste posterior para uma planta por vaso.

A areia foi adubada com todos os macronutrientes de acordo com a exigência do feijoeiro, definida conforme RIBEIRO et al. (1999), sendo 20mg $\mathrm{dm}^{-3} \mathrm{de} \mathrm{N}\left(\mathrm{CaNO}_{3}\right), 30 \mathrm{mg} \mathrm{dm}^{-3} \mathrm{de} \mathrm{K}(\mathrm{KCl}), 15 \mathrm{mg} \mathrm{dm}^{-3} \mathrm{de}$ $\mathrm{Ca}\left(\mathrm{CaNO}_{3}\right), 15 \mathrm{mg} \mathrm{dm}^{-3} \mathrm{de} \mathrm{Mg}\left(\mathrm{MgSO}_{4}\right)$ e $15 \mathrm{mg} \mathrm{dm}^{-3} \mathrm{de}$ $\mathrm{S}\left(\mathrm{MgSO}_{4}\right)$ e as respectivas doses de $\mathrm{P}$, utilizando como fonte o ácido fosfórico. Como fonte de micronutrientes, as plantas receberam semanalmente $100 \mathrm{~mL}$ vaso $^{-1}$ de solução nutritiva, segundo solução de Hoogland modificada sem fósforo, sendo a solução constituída de 2,60g L $\mathrm{g}^{-1}$ de $\mathrm{H}_{3} \mathrm{BO}_{3}$; 0,22g L-1 de ZnSO 7 $\mathrm{H}_{2} \mathrm{O} ; 1,81 \mathrm{~g}$ $\mathrm{L}^{-1}$ de $\mathrm{MnCl}_{2} 4 \mathrm{H}_{2} \mathrm{O} ; 0,08 \mathrm{~g} \mathrm{~L}^{-1}$ de $\mathrm{CuSO}_{4} 5 \mathrm{H}_{2} \mathrm{O} ; 0,99 \mathrm{~g} \mathrm{~L}^{-}$ ${ }^{1}$ de $\mathrm{H}_{2} \mathrm{MoO}_{4} \mathrm{H}_{2} \mathrm{O}$ e $7,54 \mathrm{~g} \mathrm{~L}^{-1}$ de EDTA férrico. O pH da solução manteve-se próximo a 6,0. Iniciou-se a aplicação da solução 10 dias após a semeadura, quando as folhas primárias estavam abertas (V2).

As plantas foram colhidas 45 dias após a germinação, no florescimento (R6) ou início da formação de vagens (R7), e separou-se a parte aérea e as raízes. A produção de matéria seca da parte aérea e raízes (g planta-1 ${ }^{-1}$ foi obtida após secagem em estufa à temperatura de $60^{\circ} \mathrm{C}$ por 72 horas, até massa constante. As concentrações de fósforo foram determinadas através de moagem e digestão em solução de ácido nítrico-perclórico (BATAGLIA et al., 1983).

A partir desses dados, estimou-se a resposta à adubação fosfatada de $\mathrm{P}$ pelo critério proposto por FOX (1978), com base na determinação do valor $\alpha$, onde:

$$
\alpha=\frac{\text { MSPA na } \mathrm{P}_{2}-\text { MSPA na } \mathrm{P}_{1}}{\mathrm{P}_{2}-\mathrm{P}_{1}}
$$

MSPA: matéria seca da parte aérea; $\mathrm{P}_{2}$ : alta dose (120mg dm-3 de $\mathrm{P}_{2} \mathrm{O}_{5}$ ) e $\mathrm{P}_{1}$ : baixa dose (24mg dm de $\mathrm{P}_{2} \mathrm{O}_{5}$ ).

Os dados de produção de matéria seca da parte aérea na dose mais baixa de $\mathrm{P}$ e os resultados do valor $\alpha$ de cada genótipo foram dispostos em quadrantes. Os genótipos foram então classificados em quatro grupos, sendo: ER - genótipos eficientes e responsivos, que resultam em alta produção em baixa concentração de $\mathrm{P}$ na solução e resposta à adubação fosfatada; ENR - genótipos eficientes e nãoresponsivos, que resultam em alta produção em baixa concentração de $\mathrm{P}$ na solução e baixa resposta à 
adubação fosfatada; NER - genótipos não eficientes e responsivos, que apresentam baixa produção em baixa concentração de P na solução e resposta à adubação fosfatada e NENR - genótipos não eficientes e não responsivos, que apresentam baixa produção em baixa concentração de $\mathrm{P}$ na solução e baixa resposta à adubação fosfatada.

Procedeu-se à análise de variância dos resultados e à comparação das médias pelo teste de Tukey a 5\% de probabilidade de erro.

\section{RESULTADOS E DISCUSSÃO}

Houve efeito significativo independente para doses de fósforo e genótipos de feijoeiro, assim como para a interação entre estes fatores, variando com as características avaliadas.

As maiores produções de matéria seca da parte aérea e de raízes foram conseguidas com 120mg $\mathrm{dm}^{-3}$ de $\mathrm{P}_{2} \mathrm{O}_{5}$ (tabela 1 ). A concentração de $\mathrm{P}$ no meio afeta a produção de biomassa por meio da taxa de crescimento, da partição de biomassa entre raiz e parte aérea e da taxa de absorção de $\mathrm{P}$ por unidade de raiz (NASSERY, 1970), bem como pela taxa de utilização e transformação do P inorgânico em P orgânico.

Na menor dose de $P$, as produções de matéria seca da parte aérea dos genótipos BAT 477, Jalo Precoce e Roxo foram superiores aos da média dos genótipos $\left(1,18 \mathrm{~g}\right.$ planta $\left.^{-1}\right)$. COLTMAN et al. (1985) também verificaram que linhagens de tomateiro com taxas de crescimento similares sob fornecimento adequado de $\mathrm{P}$ diferiram na produção de biomassa quando crescidas sob fornecimento insuficiente de P.
Isso mostra que esses três genótipos apresentam uma boa adaptação tanto em ambientes com deficiência como naqueles cujas concentrações de P são considerados adequadas.

Foi observada menor variabilidade na produção de matéria seca de raízes em relação à parte aérea. Segundo MARSCHNER (1995), a inibição do crescimento radicular é reduzida sob deficiência de $\mathrm{P}$, diminuindo a razão parte aérea : raiz. Segundo este autor, isso ocorre porque o decréscimo nessa relação está relacionado à elevada partição de carboidratos alocados para as raízes em plantas deficientes em $\mathrm{P}$, indicado pelo aumento na quantidade de sacarose nas raízes. Não houve diferença na produção de raízes entre os genótipos na menor dose de P. Para a maior dose de $\mathrm{P}$, os genótipos BAT 477 e Roxo apresentaram as maiores produções (tabela 1).

A razão raiz:parte aérea dos genótipos é apresentada na tabela 1 . Na menor e na maior dose de $\mathrm{P}$, apenas o genótipo Jalo Precoce diferiu dos outros, obtendo a menor razão raiz:parte aérea. Quando se compara a razão raiz:parte aérea dos genótipos nas duas doses, verifica-se que a maioria não diferiu entre si, excetuando-se BAT 477, Emgopa 201 e Rosinha. BOATWRIGHT \& VIETS JR (1966) afirmam que a razão raízes:parte aérea das plantas aumenta quando existe deficiência de $P$, o que significa maior redução no crescimento da parte aérea do que das raízes sob esta condição.

Na data da avaliação (45 dias após a germinação), as plantas de feijoeiro encontravam-se em pleno florescimento (R6) ou início da formação de vagens (R7). ARAÚJO et al. (1998) afirmam que parte

Tabela 1 - Produção de matéria seca da parte aérea e de raízes e razão raiz:parte aérea dos genótipos de feijoeiro, em duas doses de $\mathrm{P}_{2} \mathrm{O}_{5}$, 24 e $120 \mathrm{mg} \mathrm{dm}^{-3}$ na areia.

\begin{tabular}{|c|c|c|c|c|c|c|}
\hline \multirow{3}{*}{ Cultivares } & \multicolumn{4}{|c|}{ Produção de matéria seca (g planta ${ }^{-1}$ ) } & \multirow{2}{*}{\multicolumn{2}{|c|}{ Razão raiz:parte áerea }} \\
\hline & \multicolumn{2}{|c|}{ Parte Aérea } & \multicolumn{2}{|c|}{ Raízes } & & \\
\hline & $\mathrm{P}_{1}^{*}$ & $\mathrm{P}_{2}^{*}$ & $\mathrm{P}_{1}^{*}$ & $\mathrm{P}_{2}^{*}$ & $\mathrm{P}_{1}^{*}$ & $\mathrm{P}_{2}^{*}$ \\
\hline BAT 477 & $1,52 \mathrm{aB}$ & $1,80 \mathrm{aA}$ & $0,30 \mathrm{aB}$ & $0,50 \mathrm{aA}$ & $0,20 \mathrm{aB}$ & $0,28 \mathrm{aA}$ \\
\hline Carioca MG & $1,06 \mathrm{bB}$ & 1,87 aA & $0,21 \mathrm{aB}$ & 0,39 bA & $0,20 \mathrm{aA}$ & $0,21 \mathrm{aA}$ \\
\hline Emgopa 201 & $1,05 \mathrm{bB}$ & $1,47 \mathrm{bA}$ & $0,17 \mathrm{aB}$ & $0,31 \mathrm{bA}$ & $0,16 \mathrm{aB}$ & $0,21 \mathrm{aA}$ \\
\hline Jalo Precoce & $1,29 \mathrm{aB}$ & 2,26 aA & $0,18 \mathrm{aB}$ & 0,33 bA & $0,14 \mathrm{bA}$ & $0,15 \mathrm{bA}$ \\
\hline Pérola & 1,09 bB & $1,74 \mathrm{aA}$ & $0,18 \mathrm{aB}$ & $0,34 \mathrm{bA}$ & 0,17 aA & $0,20 \mathrm{aA}$ \\
\hline Rosinha & $1,11 \mathrm{bB}$ & $1,55 \mathrm{bA}$ & $0,19 \mathrm{aB}$ & $0,34 \mathrm{bA}$ & $0,17 \mathrm{aB}$ & $0,22 \mathrm{aA}$ \\
\hline Roxo & $1,21 \mathrm{aB}$ & $2,02 \mathrm{aA}$ & $0,27 \mathrm{aB}$ & 0,48 aA & $0,22 \mathrm{aA}$ & $0,24 \mathrm{aA}$ \\
\hline Xamego & $1,14 \mathrm{bB}$ & $1,68 \mathrm{bA}$ & $0,21 \mathrm{aB}$ & $0,36 \mathrm{bA}$ & $0,18 \mathrm{aA}$ & $0,21 \mathrm{aA}$ \\
\hline Média & 1,18 & 1,80 & 0,21 & 0,38 & 0,18 & 0,22 \\
\hline
\end{tabular}

Médias seguidas de mesma letra em cada variável, maiúscula na linha e minúscula na coluna, não diferem pelo teste de Tukey a 5 \% de probabilidade de erro. $\mathrm{P}_{1}$ : baixa dose de $\mathrm{P}_{2} \mathrm{O}_{5}\left(24 \mathrm{mg} \mathrm{dm}^{-3}\right) ; \mathrm{P}_{2}$ : alta dose de $\mathrm{P}_{2} \mathrm{O}_{5}\left(120 \mathrm{mg} \mathrm{dm}^{-3}\right)$ 
da variação genotípica no crescimento do feijoeiro sob baixa concentração de $\mathrm{P}$ está associada às diferenças nas datas de floração.

Na tabela 2, encontram-se os dados de conteúdo de $\mathrm{P}$ na parte aérea, nas raízes e no total, o que permite uma preliminar comparação dos genótipos, indicando a capacidade de absorção e distribuição do conteúdo de $\mathrm{P}$ dos genótipos. $\mathrm{O}$ conteúdo de $\mathrm{P}$ aumentou em todas as partes analisadas com a maior dose utilizada deste elemento. Segundo ARAÚJO (2000), a avaliação da eficiência da absorção do P, utilizando como critério somente o conteúdo de $\mathrm{P}$ acumulado pela planta, compara genótipos, mas não elucida os mecanismos responsáveis pela maior eficiência de absorção deste elemento.

O genótipo Jalo Precoce apresentou, na maior e menor dose de $\mathrm{P}$, os maiores conteúdos de P na parte aérea, não diferindo dos genótipos Roxo, Carioca MG, BAT 477, Emgopa 201 e Rosinha. Esses resultados indicam que esses genótipos possuem eficiência na absorção de P. Os genótipos Xamego e Rosinha apresentaram os menores conteúdos de $\mathrm{P}$ na parte aérea (Tabela 2).

Quanto ao conteúdo de $\mathrm{P}$ nas raízes, o genótipo BAT 477 apresentou os maiores valores, seguido por Jalo Precoce, Carioca MG e Pérola. O restante dos genótipos apresentou menores conteúdos. Esse resultado ocorreu nas duas doses avaliadas.

Quando se analisou o conteúdo de P total (parte aérea + raízes), o genótipo Xamego apresentou os menores valores nas duas doses analisadas. Para os outros genótipos, que obtiveram valores menores de conteúdo de $\mathrm{P}$ nas raízes, esses resultados foram compensados pelos valores alcançados pela parte aérea ou vice-versa. O sistema radicular acumulou menores quantidades de P que a parte aérea (Tabela 1).

A proporção do conteúdo de $\mathrm{P}$ nas raízes em relação à parte aérea foi maior sob menor concentração de $\mathrm{P}$ na solução. As plantas retiveram uma maior quantidade de $\mathrm{P}$ nas raízes em condições de deficiência de P na solução, mantendo o crescimento das raízes em relação à parte aérea. Esse fato também foi encontrado por ABICHEQUER \& BOHNEN (1998) em genótipos de trigo e por MARTINEZ et al. (1993a) em soja. Para BOATWRIGHT \& VIETS JR (1966), quando o suprimento de $\mathrm{P}$ é baixo, a proporção deste elemento retido nas raízes é mais alta que quando o suprimento é moderado. A proporção de P retido nas raízes, em relação ao conteúdo de $\mathrm{P}$ na parte aérea, foi superior na menor dose do que na dose maior de $\mathrm{P}$, sendo, respectivamente, $13,6 \%$ e 11,3\%. Este resultado está de acordo com o encontrado por ARAÚJO et al. (2000) em genótipos de feijoeiro. Quanto à percentagem de $\mathrm{P}$ absorvido na parte aérea, observa-se que o genótipo Emgopa 201 foi o que mais translocou P (90\%) e o que menos translocou foi a BAT 477 (74,9\%) (Tabela 2). GABELMAN \& GERLOFF (1983) verificaram que as diferenças na produção de biomassa em genótipos de feijoeiro sob baixo teor de $\mathrm{P}$ estiveram associadas à eficiência de utilização. Cultivares de feijoeiro deferiram no teor de $\mathrm{P}$ na folha e na taxa de utilização específica de $\mathrm{P}$ sob suprimento limitado de $\mathrm{P}$, mas não sob suprimento adequado. Dessa forma, a utilização de $\mathrm{P}$ pode ser importante componente fisiológico na seleção de genótipos tolerantes à baixa disponibilidade de $\mathrm{P}$

Tabela 2 - Conteúdo de P na parte aérea, raízes e total dos genótipos de feijoeiro em duas doses de $\mathrm{P}_{2} \mathrm{O}_{5}, 24$ e $120 \mathrm{mg}$ dm ${ }^{-3}$ na areia.

\begin{tabular}{|c|c|c|c|c|c|c|}
\hline \multirow{3}{*}{ Cultivares } & \multicolumn{6}{|c|}{ Conteúdo de P (mg planta ${ }^{-1}$ ) } \\
\hline & \multicolumn{2}{|c|}{ Parte aérea } & \multicolumn{2}{|c|}{ Raízes } & \multicolumn{2}{|c|}{ Total } \\
\hline & $\mathrm{P}_{1}^{*}$ & $\mathrm{P}_{2}{ }^{*}$ & $\mathrm{P}_{1}^{*}$ & $\mathrm{P}_{2}{ }^{*}$ & $\mathrm{P}_{1}^{*}$ & $\mathrm{P}_{2}{ }^{*}$ \\
\hline BAT 477 & $3,95 \mathrm{abB}$ & $10,15 \mathrm{abA}$ & $0,90 \mathrm{aB}$ & 2,80 aA & $4,85 \mathrm{aB}$ & $12,95 \mathrm{aA}$ \\
\hline Carioca MG & $4,89 \mathrm{aB}$ & 10,91 abA & $0,65 \mathrm{aB}$ & $1,45 \mathrm{aA}$ & $5,54 \mathrm{aB}$ & 12,36 aA \\
\hline Emgopa 201 & 4,16 abB & $11,20 \mathrm{abA}$ & $0,52 \mathrm{bB}$ & 0,98 bA & $4,68 \mathrm{aB}$ & $12,18 \mathrm{aA}$ \\
\hline Jalo Precoce & $4,98 \mathrm{aB}$ & $13,50 \mathrm{aA}$ & $0,72 \mathrm{aB}$ & 1,48 aA & $5,70 \mathrm{aB}$ & $14,98 \mathrm{aA}$ \\
\hline Pérola & $3,78 \mathrm{bB}$ & $9,81 \mathrm{bA}$ & $0,60 \mathrm{aB}$ & 1,67 aA & $4,66 \mathrm{bB}$ & $11,28 \mathrm{aA}$ \\
\hline Rosinha & 3,99 abB & 10,16 abA & $0,59 \mathrm{bB}$ & $1,21 \mathrm{bA}$ & $4,58 \mathrm{aB}$ & $11,37 \mathrm{aA}$ \\
\hline Roxo & $4,95 \mathrm{aB}$ & $12,20 \mathrm{aA}$ & $0,59 \mathrm{bB}$ & 1,20 bA & $5,54 \mathrm{aB}$ & $13,40 \mathrm{aA}$ \\
\hline Xamego & $3,44 \mathrm{bB}$ & 9,61 bA & $0,56 \mathrm{bB}$ & 1,24 bA & $4,00 \mathrm{bB}$ & $10,85 \mathrm{bA}$ \\
\hline Média & 4,27 & 10,94 & 0,67 & 1,44 & 4,94 & 12,38 \\
\hline
\end{tabular}

Médias seguidas de mesma letra em cada variável, maiúscula na linha e minúscula na coluna, não diferem pelo teste de Tukey a 5 \% de probabilidade de erro. $\mathrm{P}_{1}$ : baixa dose de $\mathrm{P}_{2} \mathrm{O}_{5}\left(24 \mathrm{mg} \mathrm{dm}^{-3}\right) ; \mathrm{P}_{2}$ : alta dose de $\mathrm{P}_{2} \mathrm{O}_{5}\left(120 \mathrm{mg} \mathrm{dm}^{-3}\right)$ 
no solo. Por outro lado, ABICHEQUER et al. (2003) verificaram que a eficiência no aproveitamento de fósforo por variedades de trigo, considerando o seu suprimento às raízes, está mais condicionada à eficiência de absorção e translocação do que à eficiência de utilização.

A eficiência de absorção está relacionada com a capacidade de absorção de maiores quantidades de P com um mínimo investimento em crescimento radicular (ELLIOTT \& LÄUCHLI, 1985). Isso pôde ser observado para o genótipo Jalo Precoce, que apresentou o maior conteúdo de $\mathrm{P}$ na parte aérea, não diferindo de outros genótipos. No entanto, o genótipo em questão exibiu um sistema radicular muito reduzido na menor dose de fósforo.

A figura 1 mostra o desempenho dos genótipos testados quanto à produção de matéria seca da parte aérea na menor dose de fósforo avaliada, o valor a (que representa a resposta dos genótipos à adubação fosfatada) e a classificação dos genótipos. Os genótipos Jalo Precoce e Roxo comportaram-se como ER. Já a BAT 477 foi classificada como ENR, Carioca MG e Pérola como NER e Emgopa 201, Rosinha e Xamego comportaram-se como NENR.

Os genótipos eficientes e responsivos (ER), como Jalo Precoce e Roxo, foram os que mais produziram em condições de baixa dose de fósforo e também responderam bem ao incremento deste elemento no substrato. Os genótipos eficientes e não- responsivos (ENR), como BAT 477, apesar de produzirem bem na dose baixa de fósforo, tiveram menor resposta ao aumento do suprimento de fósforo. Os não-eficientes e responsivos (NER), como Carioca MG e Pérola, embora tenham respondido bem ao incremento de fósforo, não alcançaram a produção de matéria seca dos genótipos ENR e ER em baixa dose deste elemento. Os genótipos não-eficientes e nãoresponsivos (NENR), como Emgopa 201, Rosinha e Xamego, produziram pouca matéria seca da parte aérea em ambas as situações.

Observou-se que o genótipo Carioca MG apresentou maior quantidade de $\mathrm{P}$ na parte aérea na menor dose de $\mathrm{P}$, porém esta maior absorção não resultou em maior produção de matéria seca, sendo este classificado como não-eficiente. Entre as características consideradas favoráveis em um genótipo de feijoeiro eficiente na utilização de P, incluem-se a translocação de $P$ das raízes para os tecidos em crescimento, a remobilização de nutrientes das folhas senescentes antes de sua abscisão e um desenvolvimento reprodutivo adequado para que a maior quantidade possível de $\mathrm{P}$ seja utilizada na produção de grãos (YOUNGDAHL, 1990). FURLANI et al. (1984) verificaram que genótipos de sorgo com maior biomassa sob baixa disponibilidade de $\mathrm{P}$ apresentaram menor taxa de absorção específica de $\mathrm{P}$, mas tiveram maior translocação de $\mathrm{P}$ para a parte aérea. Os genótipos classificados como eficientes (Jalo

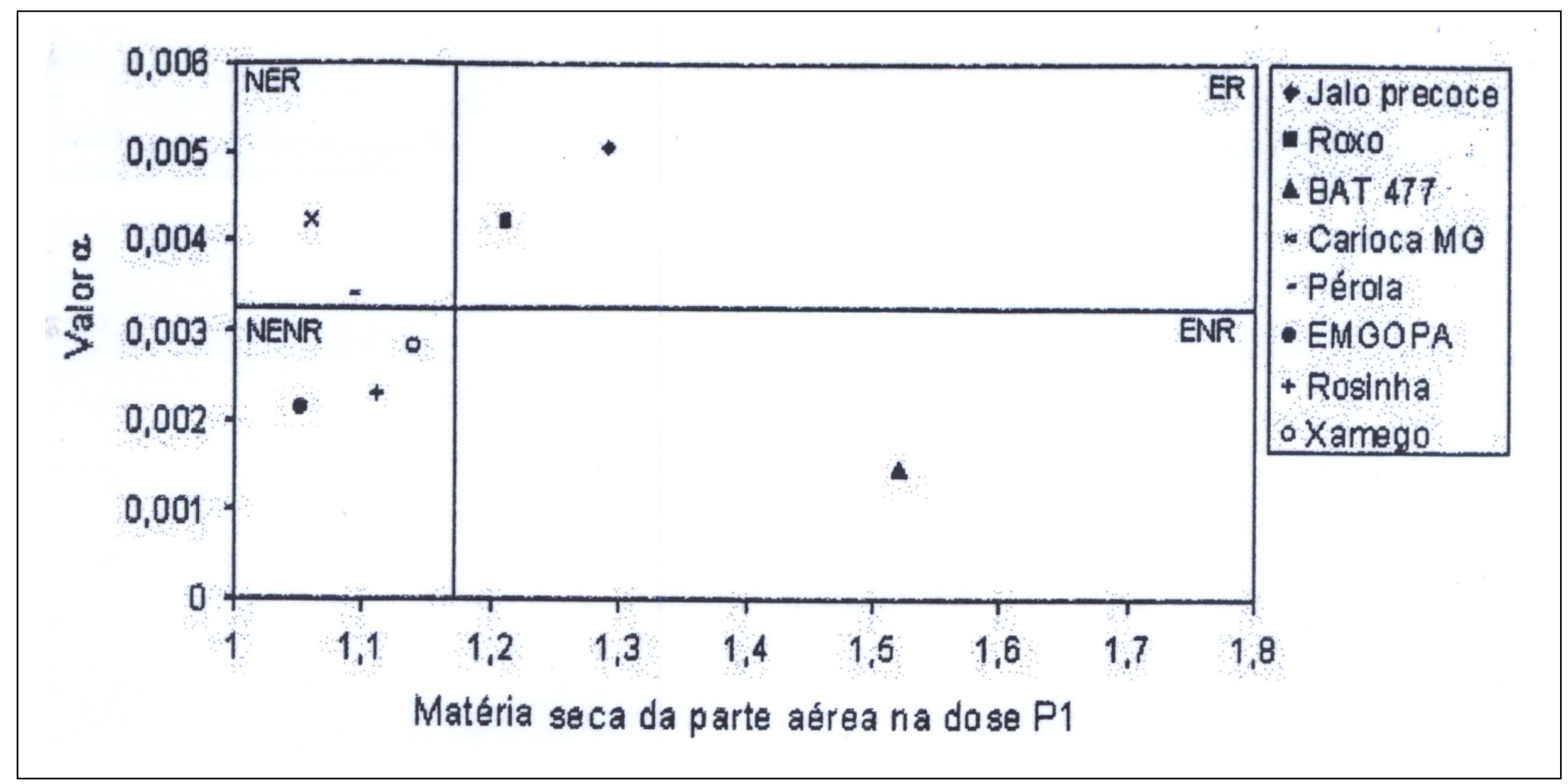

Figura 1 - Classificação de genótipos de feijoeiro quanto à eficiência de uso de $\mathrm{P}$ e à resposta à adubação. ER = eficiente e responsivo; ENR = eficiente e não-responsivo; NER = não-eficiente e responsivo e NENR = não-eficiente e não-responsivo.

Ciência Rural, v.36, n.3, mai-jun, 2006. 
Precoce, Roxo e BAT 477) absorveram mais P na menor dose e reverteram este $\mathrm{P}$ em maior produção de matéria seca. O mesmo foi verificado no trabalho de FAGERIA (1989), em que os cultivares de arroz mais eficientes na produção de grãos sob baixa disponibilidade de $\mathrm{P}$ absorveram mais P que os não-eficientes.

\section{CONCLUSÕES}

A diferença na seleção dos genótipos quanto à eficiência de uso de $\mathrm{P}$ e à produção de matéria seca está relacionada com a translocação do $\mathrm{P}$ das raízes para a parte aérea. Os genótipos classificados como eficientes na absorção e utilização de fósforo foram: BAT 477, Jalo Precoce e Roxo. Por sua vez os classificados como responsivos foram os genótipos Carioca MG, Jalo Precoce, Pérola e Roxo.

\section{REFERÊNCIAS}

ABICHEQUER, A.D.; BOHNEN, H. Eficiência de absorção, translocação e utilização de fósforo por variedades de trigo. Revista Brasileira de Ciência do Solo, Viçosa, v.22, n.1, p.21-25, 1998

ABICHEQUER, A.D. et al. Absorção, translocação e utilização de fósforo por variedades de trigo submetidas à toxidez de alumínio. Revista Brasileira de Ciência do Solo, Viçosa, v.27, n.2, p.373-378, 2003.

ARAÚJO, A.P. et al. Variability of traits associated with phosphorus efficiency in wild and cultivated genotypes of common bean. Plant and Soil, The Hague, v.203, n.2, p.173182, 1998.

ARAÚJO, A.P. et al. Growth and yield of common bean cultivars at two soil phosphorus levels under biological nitrogen fixation. Pesquisa Agropecuária Brasileira, Brasília, v.35, n.4, p.809817, 2000.

ARAÚJO, A.P. Eficiência vegetal de absorção e utilização de fósforo, com especial referência ao feijoeiro. In: NOVAIS, R.F. et al. (Eds). Tópicos em ciência do solo. Viçosa: Sociedade Brasileira de Ciência do Solo, 2000. V.1, p.163-212.

BARBOSA FILHO, M.P. et al. Aplicação de nitrogênio em cobertura no feijoeiro irrigado. Santo Antônio de Goiás: Embrapa-CNPAF, 2001. 8p. (Circular Técnica, 49).

BATAGLiA, O.C. et al. Métodos de análise química de plantas. Campinas: Instituto Agronômico de Campinas, 1983. 48p. (Boletim Técnico, 78).

BOATWRIGHT, G.O; VIETS JR, F.G. Phosphorus absorption during various growth stages of spring wheat and intermediate wheatgrass. Agronomy Journal, Madison, v.58, n.1, p.185188, 1966.

BONSER, A.M. et al. Effect of phosphorus deficiency on growth angle of basal roots in Phaseolus vulgaris. New Phytologist, Cambridge, v.132, n.2, p.281-288, 1996.
CASTELIS, A.J. et al. Absorção de fósforo como critério de seleção de genótipos de soja quanto à tolerância ao alumínio. Pesquisa Agropecuária Brasileira, Brasília, v.20, n.10, p.1163-1170, 1985.

COLTMAN, R.R. et al. Differential tolerance of tomato strains to maintained and deficient levels of phosphorus. Journal of American Society for Horticultural Science, Alexandria, v.110, n.2, p.140-144, 1985.

ELLIOTT, G.C; LÄUCHLI, A. Phosphorus efficiency and phosphate-iron interaction in maize. Agronomy Journal, Madison, v.77, n.2, p.399-403, 1985.

ERNANI, P.R. et al. Corn yield as affected by liming and tillage system on an acid Brazilian Oxisol. Agronomy Journal, Madison, v.94, n.2, p.305-309, 2002.

FAGERIA, N.K. Rice cultivars response to phosphorus nutrient solution. Pesquisa Agropecuária Brasileira, Brasília, v.24, n.6, p.699-702, 1989 .

FOX, R.H. Selection for phosphorus efficiency in corn. Communications in Soil Science and Plant Analysis, New York, v.9, n.1, p.13-37, 1978.

FURLANI, A.M.C. et al. Avaliação de genótipos de arroz quanto à eficiência na utilização de fósforo em solução nutritiva e em solo. Revista Brasileira de Ciência do Solo, Campinas, v.7, n.3, p.291-302, 1984.

GABELMAN, W.H.; GERLOFF, G.C. The search for and interpretation of genetic controls that enhance plant growth under deficiency levels of a macronutrient. Plant and Soil, The Haguen, v.72, n.2, p.335-350, 1983.

INFORZATO, R.; MIYASAKA, S. Sistema radicular do feijoeiro em dois tipos de solo do Estado de São Paulo. Bragantia, Campinas, v.22, n.2, p.477-481, 1963.

MACHADO, C.T. de T. et al. Variabilidade entre genótipos de milho para eficiência no uso de fósforo. Bragantia, v.58, p.109-124, 1999.

MARSCHNER, H. Mineral nutrition of higher plants. San Diego: Academic, 1995. 889p.

MARTINEZ, H.E.P. et al. Comportamento de variedades de soja cultivadas sob diferentes níveis de fósforo: II. Translocação do fósforo absorvido e eficiência nutricional. Revista Brasileira de Ciência do Solo, Campinas, v.17, n.2, p.239244, 1993a.

MARTINEZ, H.E.P. et al. Comportamento de variedades de soja cultivadas sob diferentes níveis de fósforo: I. Cinética de absorção de fósforo e ajustes morfológicos da planta. Revista Brasileira de Ciência do Solo, Campinas, v.17, n.2, p.231238, 1993b.

NASSERY, H. Phosphate absorption by plants from habitats of different phosphate status. New Phytologist, v.69, n.1, p.197-203, 1970.

OLIVEIRA, I.P et al. Avaliação de cultivares de feijão quanto à eficiência no uso do fósforo. Pesquisa Agropecuária Brasileira, Brasília, v.21, n.1, p.39-45, 1987. 
O’ TOOLE, J.C.; BLAND, W.L. Gentypic variation in crop plant root systems. Advances in Agronomy, New York, v.41, n.1, p.91-145, 1987.

PALMER, B.; JESSOP, R.S. Some aspects of wheat cultivar response to applied phosphate. Plant and Soil, The Hague, v.47, n.1, p.63-73, 1977.

RIBEIRO, A.C. et al. Recomendações para uso de corretivos e fertilizantes em Minas Gerais $\left(5^{\mathrm{a}}\right.$ aproximação). Viçosa: UFV, 1999. 359p.

ROSAND, P.C.; MARIANO, A.H. Absorção diferencial de fósforo em cultivares de cacau. Pesquisa Agropecuária Brasileira, Brasília, v.20, n.2, p.159-167, 1985.

SILVA, F.C. et al. Análises químicas para avaliação da fertilidade do solo. In: (Ed). Manual de análises químicas de solos, plantas e fertilizantes. Brasília: Embrapa Comunicação para Transferência de Tecnologia, 1999. p.75169 .

SMITH, F.W. et al. Internal phosphorus flows during development of phosphorus stress in Stylosanthes hamata. Australian Journal of Plant Physiology, Melbourne, v.17, n.4, p.451-464, 1990.

SMITH, S.E. et al. The involvement of mycorrhizas in assessment of genetically dependent efficiency of nutrient uptake and use. Plant and Soil, The Hague, v.146, n.2, p.169179, 1992.

YOUNGDAHL, L.J. Differences in phosphorus efficiency in bean genotypes. Journal of Plant Nutrition, New York, v.13, n.11, p.1381-1392, 1990. 